\title{
CORRESPONDENCE
}

\section{Sleep Disordered Breathing in Patients with Atrial Fibrillation and Normal Systolic Left Ventricular Function}

by Dr. med. Thomas Bitter, Dr. med. Christoph Langer,

Dr. med. Jürgen Vogt, Dr. med. Mathias Lange, Prof. Dr. med. Dieter Horstkotte, PD Dr. med. Olaf Oldenburg in volume 10/2009

\section{Neuropsychological Or Cardiological Perspective}

Concerning the diagnosis of obstructive sleep apnea (OSA) and central sleep related breathing disorders and their prevalence in patients with atrial fibrillation, the authors themselves emphasize their study's limitationnamely, that it was cardiorespiratory polygraphy that was undertaken and not an analysis of the sleep architecture. As a possible consequence, the recording period of this examination may be longer than the actual sleeping period itself, with an apnea-hypopnea index (AHI) that is set too low.

However, it is clearly more important that not performing an EEG and not analyzing sleep stages mean that no conclusions can be drawn about whether the known OSA and central SA induced psychophysiological insomnia parameters, such as microarousal, sleep fragmentation, REM or deep sleep deficits via the hypothalamic-pituitary-adrenal axis - that is, stressors that can be captured primarily by polysomnographyhave an arrhythmic effect. We have observed an association between the periodic limb movements in sleep (PLMS) with atrial fibrillation that seems too frequent to be just down to chance. The pathophysiological hypotheses concerning pressure stress and diastolic dysfunctions as a monocausal association seem less plausible to me.

DOl: 10.3238/arztebl.2009.0478a

\section{REFERENCES}

1. Bitter T, Langer C, Vogt J, Lange M, Horstkotte D, Oldenburg O: Sleep disordered breathing in patients with atrial fibrillation and normal systolic left ventricular function. Dtsch Arztebl Int 2009; 106: 164-70.

\section{Heinrich Henin}

Hagener Str. 374

44229 Dortmund, Germany

\section{In Reply:}

The pathophysiological mechanisms described by Henin represent further potential interactions between sleep related breathing disorders (BA) and atrial fibrillation.

Whether this is of clinical relevance, however, is not known to date, and is part of the obstructive and central sleep breathing disorders that can be confirmed by polygraphy. An increased coincidence of atrial fibrillation and periodic leg movements in sleep in the absence of a sleep apnea has not been described, according to the authors' own knowledge and literature searches.

However, a clearly increased prevalence of obstructive and central sleep apneas has recently been confirmed in patients with merely diastolic heart failure (1), so that an interaction between diastolic dysfunction and sleep apnea does seem rather plausible.

On the other hand, it is also known that hypoxia, hypercapnia, and hyperventilation as a result of sleep related breathing disorders promote additional activation of the sympathetic nerve. The result is an increased release of catecholamines and vasoconstrictor factors $(1,2)$, which themselves may trigger atrial fibrillation.

An induction of atrial fibrillation by the hyperventilation and apnea phases thus seems plausible.

Ultimately the causality of the interaction between atrial fibrillation and SBA is multifactorial. Further studies are therefore required to clarify the importance of individual factors and their relations.

DOI: 10.3238/arztebl.2009.0478b

\section{REFERENCES}

1. Bitter T, Faber L, Hering D, Langer C, Horstkotte D, Oldenburg O: Sleep disordered breathing in heart failure with normal left ventricular ejection fraction. Eur J Heart Fail 2009; 11: 602-8.

2. Brooks D, Horner LJ, Kozar LF, Render-Teixera CL, Philippson EA: Obstructive sleep apnea as a cause of systemic hypertension. Evidences from a canine model. J Clin Invest 1997; 99: 106-9.

3. Calhoun DA, Nishizaka MK, Zaman MA, Harding SM: Aldosterone excretion among subjects with resistant hypertension and symptoms of sleep apnea. Chest 2004; 125: 112-7.

4. Bitter T, Langer C, Vogt J, Lange M, Horstkotte D, Oldenburg 0: Sleep disordered breathing in patients with atrial fibrillation and normal systolic left ventricular function. Dtsch Arztebl Int 2009; 106: 164-70.

\section{Dr. med. Thomas Bitter}

Kardiologische Klinik

Herz- und Diabeteszentrum Nordrhein-Westfalen

Ruhr-Universität-Bochum

Georgstr. 11

32545 Bad Oeynhausen, Germany

akohlstaedt@hdz-nrw.de

\section{Conflict of interest statement}

The authors of both the letter and of the reply declare that no conflict of interest exists according to the guidelines of the International Committee of Medical Journal Editors. 